\title{
Determination of the solar transmittance for the translucent shutter with PCM in liquid and solid state
}

\author{
Anna Komerska ${ }^{1,}$, Dariusz Ksionek $^{1}$, and Marian Rosiński ${ }^{1}$ \\ ${ }^{1}$ Warsaw University of Technology, Faculty of Building Services, Hydro and Environmental \\ Engineering, ul. Nowowiejska 20, 00-653 Warsaw, Poland
}

\begin{abstract}
This article presents results of the energy performance of an external translucent shading component integrated with a phase change material. A proposed technology is able to accumulate considerable amounts of energy in the latent heat by absorbing solar energy. Due to selective optical properties, much of the visible light is still transmitted through the facade. Experimental measurements were carried out in a laboratory set-up - testing thermal chamber, located in the Faculty of Building Services, Hydro and Environmental Engineering at Warsaw University of Technology. The main result of the experimental study was the evaluation of the average solar transmittance in the whole measured spectrum, as well as in the infrared and visible light. Since the shift in optical properties was observed when the material was undergoing a phase transition, the average spectral transmittances were measured for different states of matter of the PCM material. The tested shutter showed abilities to reduce and modulate daylight and solar heat gains in the indoor environment, which could contribute to considerable energy savings.
\end{abstract}

\section{Introduction}

The fenestration components are still responsible for a significant share in the building energy consumption. Glazed façades, characterised by poor thermal inertia and high heat transfer coefficient, present a weaker energy performance if compared to opaque building elements. During high solar radiation, they play a major role in the internal solar heat gains leading to an increase in the energy need for cooling, overheating problems or thermal discomfort. The most common solutions to decrease solar heat gains applied by engineers focus mainly on the conventional shadings with adequate shading strategy. However, some new solutions are currently under development. New technologies aimed at reducing the solar transmittance include suspended films, aerogel insulation, solar cells or smart materials able to modulate their properties such as thermo- electro- or photochromic materials [1]. The main drawback of most of them is still high investment cost. Another idea based on material's switchable properties and translucent features could be a shading system with a phase change material.

\footnotetext{
*Corresponding author: anna.komerska@is.pw.edu.pl
} 
Some of the PCMs are able to accumulate considerable amounts of energy in the latent heat. Due to material's selective optical properties, it absorbs considerable amount of infrared light while much of the visible light is still transmitted through the façade [2-5]. Researchers investigated different PCM glazing systems depending on the way the phase change material was integrated into the façade. One of the solution was to fill the window cavity with a PCM [6-10], another idea was to integrate it with a shading and create PCM blinds or shutters $[2,11-16]$. The main advantages of this solutions reported by the researchers, was the improvement of the thermal inertia of the façade and the reduction and time shift of the internal solar heat gains.

The main role of shading technologies with a PCM is to decrease the level of the solar heat gains by the absorption of the infrared part of the solar radiation and transmission of the visible light. The investigation of the thermal energy assessment of the proposed shutter proved positive effects on the façade [16]. This paper is however, focused only on the optical properties of the investigated technology. The average spectral transmittances in visible and infrared light were determined through experimental measurements conducted in a thermal chamber in controlled environment.

\section{Materials and methods}

\subsection{System description}

The technological concept of the analysed shading is a translucent shutter, consisted of phase change material enclosed in a polycarbonate panel. Due to selective properties of the PCM the shutter is able to absorb considerable amounts of solar radiation in the infrared part of the spectrum and therefore prevent room from high solar heat gains. The PCM also transmits more visible light that IR so the visual comfort inside the building could be still maintained. Moreover, in solid state, high scattering properties of the PCM prevent occupants from a glare risk. The thermo-optical properties of the PCM are however not constant. The shutter is a type of a responsive behaviour shading with optical coefficients dynamically changing along with the temperature and the phase change state.

The tested panel was designed for an external application with dimensions $70 \mathrm{~cm} \times 70 \mathrm{~cm}$, cavity of $1 \mathrm{~cm}$ and weight of approximately $9 \mathrm{~kg} / \mathrm{m}^{2}$. A paraffin based PCM was selected with the nominal melting temperature of $31^{\circ} \mathrm{C}$, with the heat storage capacity of around $165 \mathrm{~kJ} / \mathrm{kg}$. During sunny days, when the panel is exposed to high solar radiation, it absorbs heat and increases its temperature, up to its meting temperature. Since the latent heat represents much higher value than the heat capacity, equal to approx. $2 \mathrm{~kJ} \cdot \mathrm{kg}^{-1} \cdot \mathrm{K}^{-1}$, the panel maintains its temperature for considerably long time until it completely liquidises. To avoid reducing daylighting during cloudy days, it can be used also as a movable shading.

\subsection{Experimental set- up}

The experiments were conducted in a testing thermal chamber (

Fig. 1a), located in the Faculty of Building Services, Hydro and Environmental Engineering at Warsaw University of Technology. The chamber is equipped with a ventilation system ensuring stable thermal conditions inside the test cell. Solar radiation is provided by a solar simulator consisted of four metal halide lamps with the total power of $1.6 \mathrm{~kW}$. Special reflectors ensured acceptable uniformity of the irradiance level over the tested sample.

The tested panel was mounted horizontally in front of the solar simulator. During the measurements, lamps provided an irradiation of approximately $1000 \mathrm{~W} / \mathrm{m}^{2}$ classified as one sun. Solar spectrum of AM $=1.5$ according to standards ISO 9050, ASTM G173 is used in 
solar industry for all standardized testing and therefore is acknowledged as a reference in solar simulators. Two pyranometers LP PYRA were used to measure the solar radiation transmitted through the tested panel in two different locations. The transmittance for visible and infrared spectrum was additionally measured by applying on the pyranometers suitable optical filters: UV and VIS filter - Heliopan $62 \mathrm{~mm}$ Infra Red $715 \mathrm{~nm}$ used for measuring transmittance in the infrared light, UV and IR filter - Heliopan Digital UV/IR used for measuring transmittance in visible light. The temperature of the surface of the panel as well as the temperature in the cell was monitored with the use of resistance thermal sensors Pt 100. An aluminium shield was placed over the sensors in order to protect them from direct radiation. The state of the PCM was defined through temperature sensors as well as through visual assessment.

The measurement protocol applied in the characterization of the solar transmittances presents however, some limitations. Main issues that could influence the results are related to the spectral distribution of the solar simulator which does not ideally reflect the solar spectrum or to the uniformity of the generated light.

a)

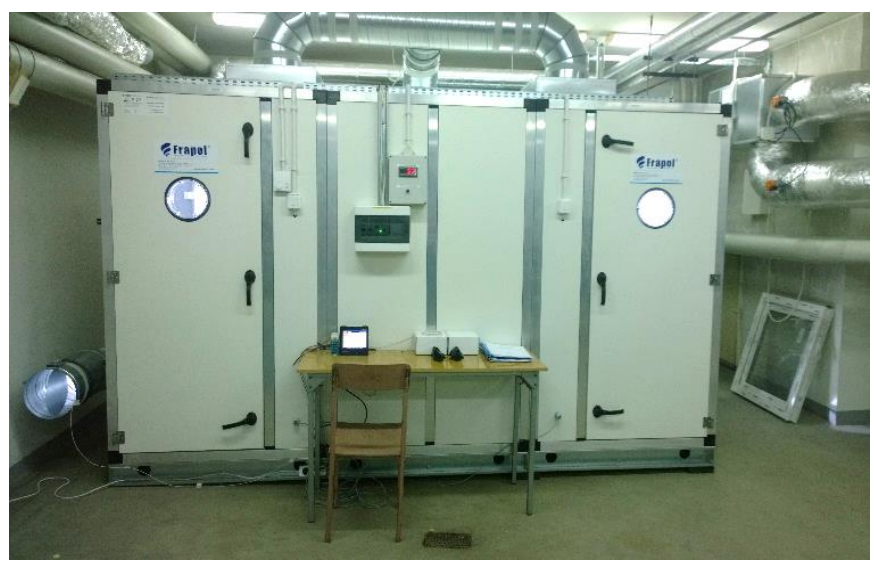

b)

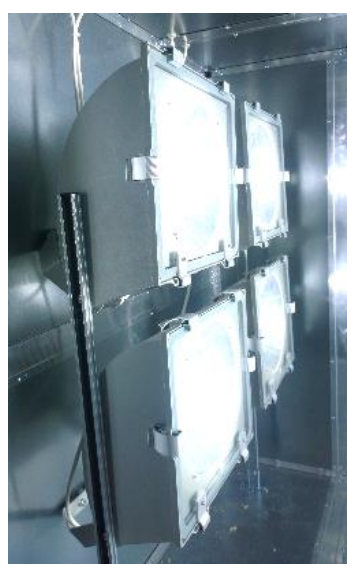

Fig. 1. a) view of the thermal chamber; b) view of the solar simulator.

\subsection{Methods - measuring parameters}

The experimental procedure was composed of subsequent measurements. Firstly, tests were conducted with the absence of the PCM shutter in order to obtain the level of total and spectral (VIS and NIR) solar radiation generated by solar simulator. The visible spectrum was measured in a spectral range of 380-705 nm, the infrared spectrum: 705-3000 nm. Measured values were afterwards used as a reference to calculate the transmittance coefficients of the panel. Second stage focused on the determination of the total and spectral (VIS and NIR) radiation transmitted through the panel. The full set of measurements was taken for solid and afterwards for liquid state of the PCM. Temperatures and irradiances were collected every 30 seconds. The data used for calculations represents 5 minutes of continuous measurements of each stage. The solar transmission coefficient was calculated as the ratio between solar radiation transmitted and incident on the panel. The average coefficient value represents a mean value of 10 subsequent measurements. Measurement inaccuracy of solar irradiances caused by non-ideal characteristics of optical filters was increased through a correction factor, determined through additional measurements and the technical datasheet. For the sake of brevity, the methodology of this procedure is not included in this paper. 
a)

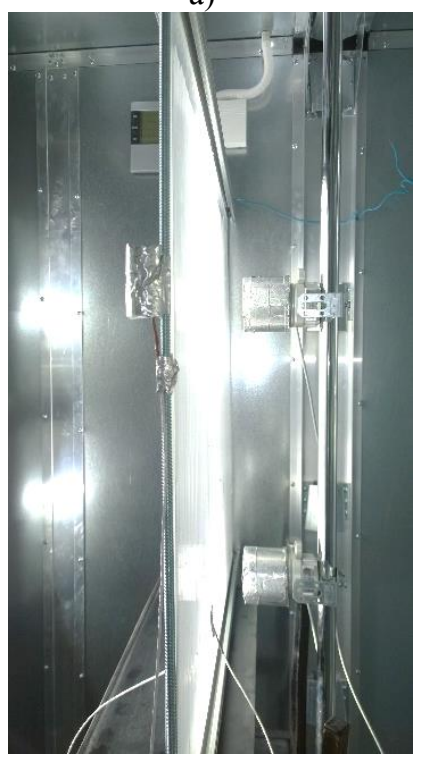

b)

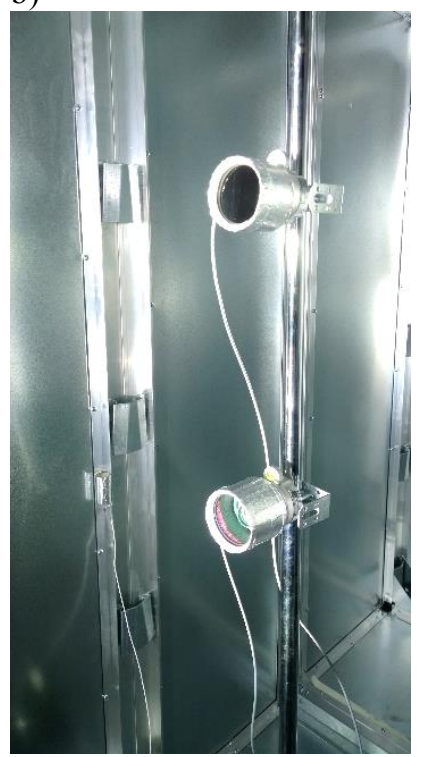

c)

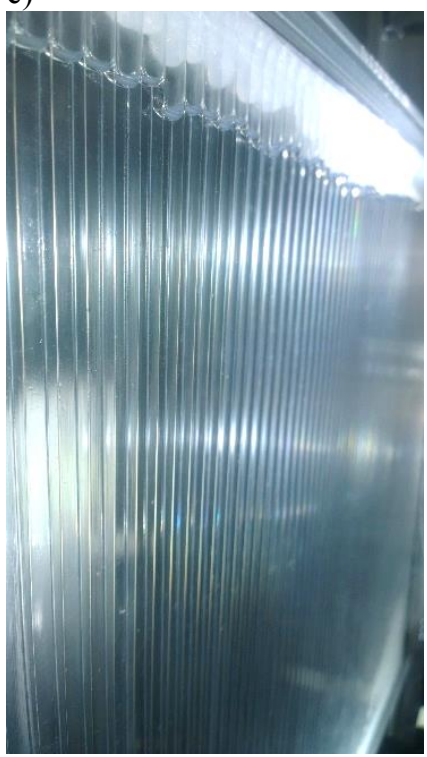

Fig. 2 a) measurements of the solar irradiance transmitted through PCM panel; b) measurements of the spectrum of the solar simulator using optical filters; c) tested shutter with liquid PCM.

\section{Results and discussion}

The average solar transmittances, were summarised in Table 1. The level of the measured solar irradiances collected from both pyranometers is shown in

Fig. 3. In order to compare transmittances for each studied case, solar irradiances were categorised with the state of aggregation of the PCM and the spectral band.

Table 1. Average transmittance coefficients of the investigated shutter.

\begin{tabular}{|c|c|c|c|c|c|c|}
\hline \multirow{2}{*}{ State of PCM } & \multicolumn{2}{|c|}{$\mathbf{t}_{\text {tot }}$} & \multicolumn{2}{c|}{$\mathbf{t}_{\text {vis }}$} & \multicolumn{2}{c|}{$\mathbf{t}_{\text {nir }}$} \\
\cline { 2 - 7 } & \multicolumn{2}{|c|}{$[-]$} & \multicolumn{2}{c|}{$[-]$} & \multicolumn{2}{c|}{$[-]$} \\
\cline { 2 - 8 } & $\begin{array}{c}\text { upper } \\
\text { sensor }\end{array}$ & $\begin{array}{c}\text { lower } \\
\text { sensor }\end{array}$ & $\begin{array}{c}\text { upper } \\
\text { sensor }\end{array}$ & $\begin{array}{c}\text { lower } \\
\text { sensor }\end{array}$ & $\begin{array}{c}\text { upper } \\
\text { sensor }\end{array}$ & $\begin{array}{c}\text { lower } \\
\text { sensor }\end{array}$ \\
\hline liquid & 0.82 & 0.82 & 0.88 & 0.88 & 0.74 & 0.79 \\
\hline solid & 0.38 & 0.36 & 0.37 & 0.35 & 0.31 & 0.32 \\
\hline
\end{tabular}

Results showed selective optical properties of the PCM shutter. The solar transmittances varied depending on the state of aggregation of the PCM as well as on the analysed spectral band. When PCM was in solid state the transmittance of the panel represented a low value of approx. 0.37 due to high scattering properties and the light absorption of the crystalized PCM. As expected, the optical properties of the investigated panel changed when the PCMs went through a phase transition process. Melting of the PCM resulted in an increase of the average total transmitted irradiance from $373 \mathrm{~W} / \mathrm{m}^{2}$ to $823 \mathrm{~W} / \mathrm{m}^{2}$, visible irradiance from $201 \mathrm{~W} / \mathrm{m}^{2}$ to $497 \mathrm{~W} / \mathrm{m}^{2}$, IR irradiance from $118 \mathrm{~W} / \mathrm{m}^{2}$ to $291 \mathrm{~W} / \mathrm{m}^{2}$. Moreover, the investigated shutter proved to transmit more energy in visible light than in infrared band. The level of transmitted 
solar radiation through the shutter with solid PCM was found to be approximately 1.71 times higher for visible than for infrared light. In a case when the PCM was completely melted, the ratio represented similar value of 1.70 .

As shown in Table 1 small variances in solar transmittances between both sensors can be observed. This issue could be caused by the inhomogeneity of the PCM material. When PCM solidifies, it decreases its volume. If the crystallisation process runs too fast, air cannot escape to the top of the panel and therefore small air bubbles are trapped inside the phase change material.

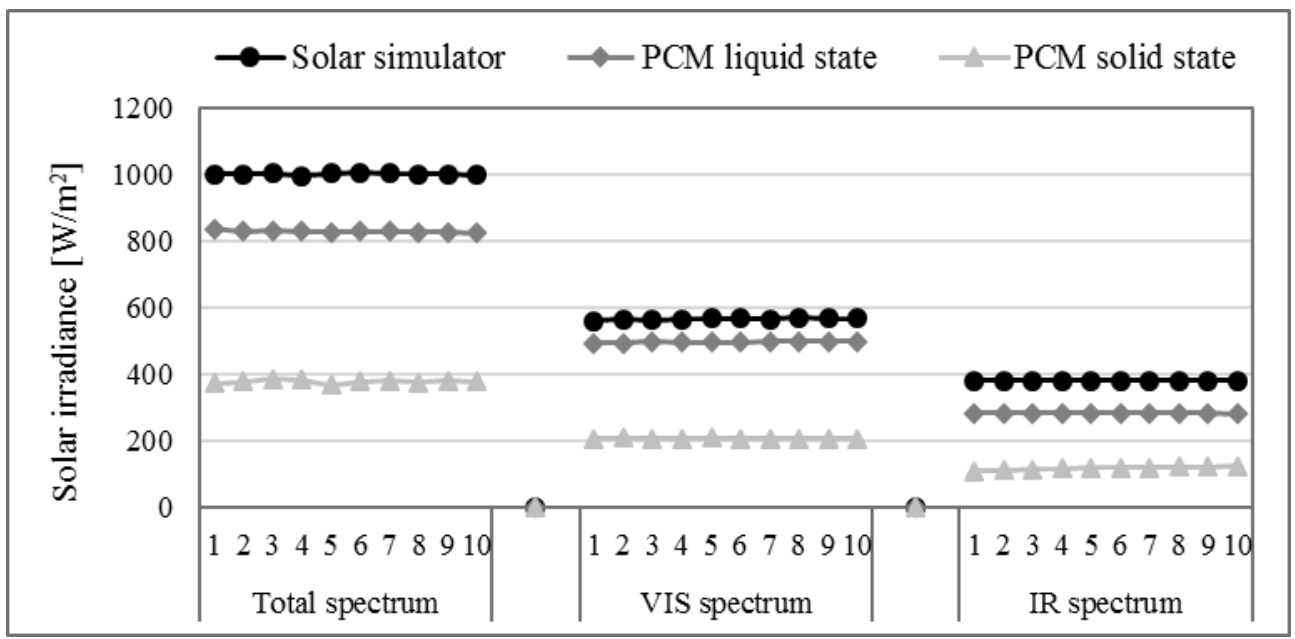

Fig. 3 Total and spectral solar radiation incident and transmitted through the tested shutter in a function of 10 subsequent measurements.

\section{Conclusions}

The analysed panel is designed to act as a solar shading that improve the thermal performance of the glazed façade. The technological concept is based on selective optical properties of the paraffin wax for different spectral bands. Especially PCM's ability to absorb infrared light and transmit high value of visible light. Such system can decrease the internal solar heat gains, prevent form the glare risk however, still provide daylight and visual comfort inside the room.

The study was focused on the determination of the transmittance coefficients in visible and infrared band. The results showed high potential of the panel in reducing solar heat gains while still providing visible light transmittance. The solar transmittances varied depending on the state of aggregation of the PCM as well as on the analysed spectral band. In solid state the panel transmitted approximately $31 \%$ of the IR and $36 \%$ of the visible light. When the PCM became liquid, the transmittances increased reaching value of $77 \%$ and $88 \%$ respectively. Both in solid and liquid state the transmittance coefficients in the infrared spectrum were therefore lower than for the visible band.

This research was performed with the financial support of Warsaw University of Technology, Faculty of Building Services, Hydro and Environmental Engineering, grant No.: 504/02638/1110/42.000100 and grant No.: 504/02639. Authors would like to thank the company Frapol for their kind help in developing and building a thermal chamber. Especially, we acknowledge the contribution and support of Mr Grzegorz Mars. 


\section{References}

1. P.J. Bjørn, A. Hynd, A. Gustavsen, D. Arasteh, H. Goudey, R. Hart, Sol. Energ. Mat. Sol. Cells 96, 1-28 (2012)

2. H. Weinlader, A. Beck, J. Fricke, Sol. Energy 78, 177-186 (2005)

3. F. Goia, M. Zinzi, E. Carnielo, V. Serra, Energy Procedia 30, 428 - 437 (2012)

4. B.L. Gowreesunker, S. B. Stanković, S.A. Tassou, P.A. Kyriacou, Energy Build. 61, 239-249 (2013)

5. D. Li, Z. Yumeng, Z. Li, H. Qi, Energy Build. 108, 381-386 (2015)

6. F. Frontini, J. Pfafferot, S. Herkel, D. Schwrtz, CISBAT (2011)

7. S. Li, Y. Zhou, K. Zhong, X. Zhang, J. Xing, International Journal of Low-Carbon Technologies Advance Access (2013)

8. S. Grynning, F. Goia, E. Rognvik, B. Time, Passivhus norden (2012)

9. F. Goia, M. Perino, V. Serra, Sol. Energy 100, 217-233 (2014)

10. F. Goia, L. Bianco, Y. Cascone, M. Perino, V. Serra, Energy Procedia 48, 1272-1281 (2014)

11. H. Weinlaeder, W. Koerner, M. Heidenfelder, Energy Build. 43, 2468-2475 (2011)

12. N. Soares, J. J. Costa, A. Samagaio, R. Vicente, World Renewable Energy Congress (2011)

13. E.M. Alawadhi, Energy Build. 47, 421-429 (2012)

14. R. Ryu, S. Janghoo, K. Yongseong, Contemp. Eng. Sci. 7, 21, 1005-1012 (2014)

15. T. Silva, V. Romeu, F. Rodrigues, A. Samagaio, Energy Build. 88, 110-121 (2015)

16. A. Komerska, L. Bianco, V. Serra, S. Fantucci, M. Rosiński, Energy Procedia 78, 3452-3457 (2015) 